\title{
Fortbildung „Ultraschall-Abschlusskurs“
}

\section{2./13.07.2013 in Nürnberg nach den Richtlinien der DEGUM und der KVB}

\section{Ziel und Inhalte des Kurses}

$\nabla$

Der Abschlusskurs vermittelt im theoretischen Teil Kenntnisse zu häufigen als auch selteneren pathologischen Veränderungen der Bauchorgane und angrenzender abdomineller Strukturen sowie der Halsregion. Differenzialdiagnostische Erwägungen werden mit einbezogen. Der Stellenwert der Sonografie wird bei gängigen klinischen Problemstellungen erörtert.

Der Kurs ist auch als Refresherkurs zur Auffrischung der Ultraschallkenntnisse geeignet. Im Praxisteil haben die Teilnehmer die Möglichkeit, pathologische Befunde an Patienten selbst zu erheben.
Der Kurs bietet Live-Demonstrationen und Untersuchungen von Patienten. Die Patienten stammen aus allen beteiligten Fachbereichen.

Interdisziplinärer Kurs in Zusammenarbeit mit den Medizinischen Kliniken und der Radiologie Nord des Klinikums Nürnberg.

Kursinformationen
Veranstalter:
Akademie für Fort- und Weiterbildung in
der Radiologie
Ernst-Reuter-Platz 10, 10587 Berlin

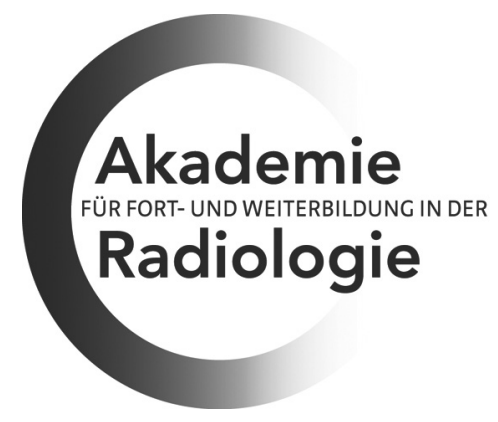

\section{Kontakt}

Frau Birgit Engelhardt

E-Mail: engelhardt@drg.de Tel.: 030/91607016

\section{Anmeldung \\ Online unter} www.drg.de (Veranstaltungshinweise) 